\title{
Silencing dissent in an online discussion forum of a higher education institution
}

\author{
L POSTMA ${ }^{1}$ AND AS BLIGNAUT ${ }^{2}$
}

\begin{abstract}
In an online forum at a higher education institution in South Africa, interventions from management in order to moderate discussions, result in antagonism and the smothering of dissident discourse. Critical poststructuralist theory, the model of communicative democratic discourse as held by Iris Marion Young, and the tenets of ideal speech as held by Jürgen Habermas, inform the study while it investigates how the internal and external moderation of the forum limit and terminate essential discourse which could be instrumental in the critical construction of meaning and the exercise of freedom of speech. The methodology of grounded theory and the approach of critical discourse analysis direct the exploration of interview transcripts and forum text. In the analysis of characteristics displayed in discursive moderating strategies, the researchers are enabled to propose a form of emancipatory moderation within the discourse which could result in better understanding among opposing parties. The hegemonous and distant character as seen in the discourse concerning current moderation is subversed to allow participatory and equal moderation for the establishment of an enabling, accepting and diverse online environment.
\end{abstract}

Keywords: moderation of online forum; higher education institution; freedom of speech; censorship; democratic discourse

Universities are ideally world seminar rooms, which offer opportunities to openly shape, share and debate ideas to ultimately find truth. In this context freedom of speech plays a central role and forms a basic prerequisite and right for the development of academics. Williams (as referred to by Dandridge and Mendus, 2012) however insists that freedom of speech for academics as well as the ideal of an open university is challenged within the "highly regulated context of universities."

An online discussion forum of a formerly mono-cultural higher education institution in South Africa was established with the objective in mind that employees could raise issues and share ideas in such a virtual seminar room. With the transformation of the university to a multi-racial institution, anxiety levels among employees rose. Those in favour of the transformation used the forum to voice their opinions about remaining hegemonous and unemancipatory practices, while those with cataclysmic views about political and institutional transformation opposed the so-called liberals and expressed nostalgia about the time before transformation.

1. Dr Louise Postma is attached to the School Education Studies, Faculty of Education Sciences, Potchefstroom Campus of the North-West University. Email: Louise.Postma@nwu.ac.za.

2. Prof. Dr A Seugnet Blignaut is Research Professor, School of Natural Sciences and Technology Education, Faculty of Education Sciences, Potchefstroom Campus of the North-West University. Email: Seugnet.Blignaut@nwu.ac.za. 
Although these opinions are divergent, the ideal would be that they could be expressed in an environment which is secure and equalizing (Herring et al., 2002). In such an ideal university context, participants of different academic positions, cultural identities and divergent perspectives can freely raise issues of concern. This can be done without the status-related differences (O'Sullivan and Flanagin, 2003) which characterise and inhibit offline interactions. The presumed equalization of participants plays a motivating role, with the assumption that this alternative space offers the opportunity for free expression which might not be found elsewhere. In contrast to this ideal perspective of participants, or their "enabling logic," some participants and members of management condone a "control logic" (De Laat, 2012: 1) in the moderation of the forum and expect external intervention by way of censoring or controlling those with extremist and dangerous points of view.

This paper describes how the rationalistic and moralistic context of internal and external moderation of the online discussion forum excludes participants. It aims to illustrate which participations are perceived as extremist and socially dangerous and how these participants' voices are silenced. By these forceful acts, the proponents of the ideal speech situation (ISS) which Habermas (1990) characterizes as the absence of oppression and dominance are undermined. The central thesis of the paper is that moderating interventions are not aimed to reach a consensus and the common good of the ISS, but driven by normalistic and moralistic concerns limiting online and offline uncomfortable positions in order to protect managerial and strategic concerns and to ignore and avoid conflict. These interventions do not facilitate the discourse towards expressing correct views in a moderate and refined way, but lead to more ${ }^{3}$ flaming and ${ }^{4}$ trolling (Herring et al., 2002; Turnage, 2007) on the forum, a growing intolerance between discussants, non-constructive and disruptive comments, and the termination of participation. The opportunity for academics to learn the truth is sabotaged, as the discomfort which management experiences in interacting with perceived irrational and unreasonable participations leads to the silencing of voices. Instead of facing and dealing with uncomfortable views, the discourse on challenging issues is censored, which ultimately terminates real and potential voices.

The online and offline community of like-minded participants lends intellectual capital and authority to academic participations which assume rationalistic, detached and clinical positions, while more involved, emotional and seemingly ill-judged participations are perceived as intellectually inferior. This "Bourdieusian intellectual capital" (Wodak, 1996: $25,26)$ is dominant in the forum, contributing to the agreement that participations representing opposing world views have less learned styles and are consequently disregarded or acted on by way of some form of external moderation. External moderation eventually adds to the imbalance of power in the forum, which has already been caused by the internal dominance of rationalistic participations.

3 An online argument that becomes nasty or derisive, where insulting a party to the discussion takes precedence over the objective merits of one side or another. X was flaming Y over his religious beliefs Urban Dictionary. (2013a) Flaming. Available at: http://www.urbandictionary.com/define.php?term=flaming.(Urban Dictionary)

$4 \quad$ One who posts a deliberately provocative message to a newsgroup or message board with the intention of causing maximum disruption and argument Urban Dictionary. (2013b) Trolling. Available at: http://www.urbandictionary.com/define.php?term=troll.(Urban Dictionary "Trolling") 
The verb "moderate" has a Latin root, which explains "modus" as "a medium quantity or quality" and the verb "moderare" as the action "to avoid extremes" (Hoad, 1996). Understood in the context of the paper, the act of moderation would mean to avoid extreme voices. A moderation of extreme voices on an online forum would be interpreted in the paradigm of deliberative democracy (Habermas, 1990) to bring opposing parties to a form of consensus. The paradigm of communicative democracy of Young (2000) however, would as an act of moderation allow opposing and extremist voices to occupy their places by way of different strategies. Young (2000) refers to these strategies as an emotive rhetorical process to bring opposing parties to the understanding of differences and specific situations and not necessarily to a rational agreement. Echoing Young's (2000) insistence on emotive strategies in discourse, the postmodernist position on knowledge holds that "truth and knowledge are not only to be found through rational thought or method" (Webster and Mertova, 2007: 29), but also through emotional experience, which embodies both discomfort and conflict. Critical poststructuralist theory, which informs this study, stresses subjectivity, emotionality and feeling (Denzin, 1999: 113), elements which are acknowledged, advocated and regarded by Young (2000) as prerequisite elements in the understanding of others, the legitimization of their voices and eventually the democratization of everyone through discourse. This implies that moderation should not become a means to silence the so-called extreme voices but rather create the means for these to be heard.

Instead of enabling participants to speak their minds, the act of speaking out is used by moderating interventions as a means to control, limit and eventually disable freedom of speech. The forum enhances the visibility of those who participate and ultimately function in a "Foucaultian panopticon" (Foucault, as cited by Rouse, 2003), which implies that the forum offers management a means to see everything and to eventually control what they see. Moderation becomes what Foucault describes as "control or neutralization of dangerous social elements" (as cited by Rouse, 2003: 100). Eventually a person whose participation causes discomfort with readers and moderators is literally overpowered. In this respect Foucault's explanation of power as the "right of seizure: of things, time, bodies, and ultimately life itself" is relevant (as cited by Rouse, 2003: 100), as these moderating interventions resulted in trauma, time to be spent in dealing with the processing of trauma and the termination of life on the forum. Even if the participation is in a virtual space and reality is represented through discourse, participants also create reality through discourse. This presented or created reality is just as real as face to face discourse, as it influences real life and can potentially lead to trauma. The virtual does matter and becomes "embodied matter" (Van Doorn, 2011). The fact that participation happens in a virtual space, does not diminish the reality of its influence. Participants in virtual space are materialized, or embodied through their presentations of themselves: "In this sense, the performative practices in digital spaces...resemble everyday physical experiences in their simultaneous incorporation of virtual and concrete elements to make sense of daily life...the digitally virtual is embedded in the ongoing life of the concrete and forms an important extension of the notions of reality and the context of action" (Shields, as cited by Van Doorn, 2011: 534). One can therefore conclude that the moderation of online participations is not experienced lightly and superficially as it serves as a significantly negative intervention in the participants' lives.

This paper focuses on the moderation of the online forum: (i) by using grounded theory methodology and critical discourse analysis (Wodak, 1996), the researchers analyse the text of and interviews with participants who directly or indirectly experienced, feared, condoned or 
enforced the processes of moderation, and (ii) by formulating hypotheses and proposals they contribute to the establishing of theory of an alternative form of moderation.

\section{Moderating interventions}

Grounded theory methodology (Strauss and Corbin, 2008) directs the empirical part of the study, allowing the researchers to formulate theory concerning moderation as the final stage of analysis. The following diagram illustrates the relationship between the different categories which were established through the procedure of selective coding. In this presentation of data, it is evident that the moderating interventions influence all the aspects of participation. In the discussion which follows, the paths indicated between categories will be referred to. The participants who are referred to in the next section, either condoned or practised forms of moderation, or were subjected to it. Moralistic and rationalistic elements in their moderating discursive interactions with participants, effect the exclusion of dissidents or those who oppose the normalistic view.

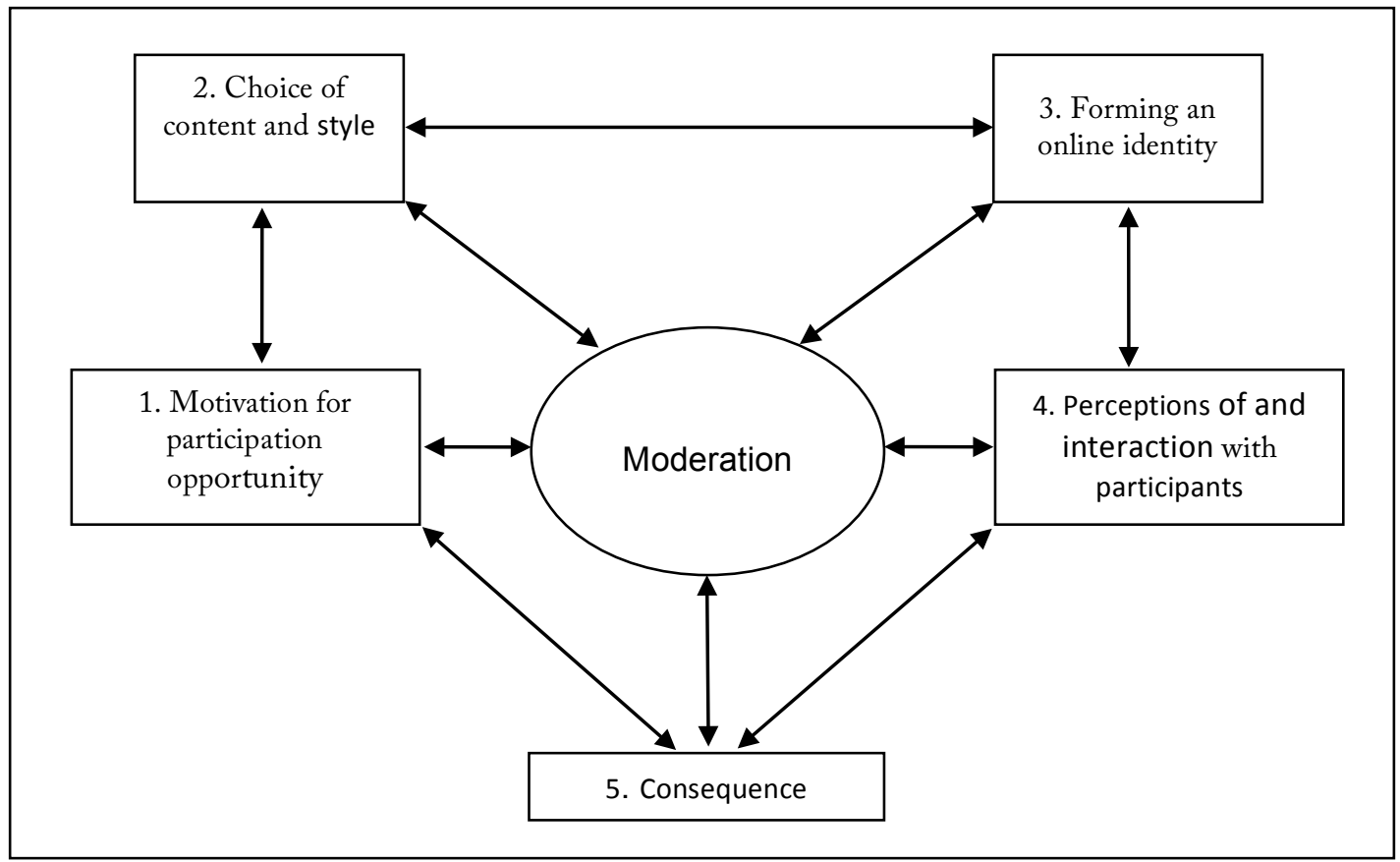

Figure 1 Categories to which moderation links

\section{The voice of the people}

In her time as member of the institution's management, Cathy acted as the unannounced moderator of the forum. During the interview with the researcher, she states her perception of the forum as a useful therapeutic space (Figure 1:1) where employees could during the uncertain time of transformation to a racially integrated institution, voice their honest opinions. She also regards the forum as a place where people could make unguarded statements if they were afraid to do so elsewhere: 
Cathy: And, people are very hesitant to say things directly to you, uh, I think you know...can be a career limiting statement, or they think it is not quite appropriate to load you with unimportant stuff, of they are afraid that they might offend you, all those type of things which out of a, uh, look, the relationship between a senior manager and someone lower down in the organization is a skew relationship of power and of course people are, uh, there are many filters which people build in to make sure that they protect themselves also, and [the forum sic] has always been, uhm, to me one of the very best ways to find out what the people really think.

As Cathy regrets the collegial distance which was created by the style of management in the new context of a larger university, being a former outspoken academic herself, she perceives the forum to be the "voice of the people." The forum provides opportunity (Figure 1:1) to criticize management, which offers a useful insight in what is happening at grass roots level and which serves as a bridge for her to cross the divide between management and employees:

Cathy: Look, I think it is very important when you are in a, in a management position, that you have to know what people think and say, because, uh, one moves a bit, especially when you are on the level of campus management, that you do not have much to do with people much lower down on the food chain, to call it like that... And the forum has always been to me, uhm, one of the best methods to get to know what people are really thinking, because I think that people who write on the, uhm, forum, that they, uhm, don't think that senior management will read it, so they are more free or they, uhm, think that you will read it and it provides them with the opportunity to deliver a bit of a blow or whatever, but is has always been to me in the largest extent an opportunity to hear, what the, what the people are thinking.

Since Cathy shows a regular and keen interest in forum activities, she is alerted by her secretary or family members about actions on the forum which they regard would be of importance to her when she herself cannot tend to it. She acknowledges that, in stressful times, the forum served as relief (Figure 1:1), as difficult situations were often defused with witty remarks on the forum. In this regard she perceives the forum as a place which provides much needed fun and entertainment, serving as a therapeutic space for her personally.

\section{The significance for management}

Although she has a benevolent feeling towards forum activities, Cathy acknowledges the dismissiveness of certain members of management about the forum:

Look, there were some members of management who distanced themselves totally from [the forum sic], who felt, ob no, you know, I am not tiring myself.

She adds that the forum creates awareness with management about strong feelings (Figure 1:1), although she can't perceive that the forum effected any structural changes:

Cathy: You know, I cannot...see that it had in such a measure an impact, and then I cannot say that we said in meetings listen here, what was on the [forum sic] again, and how can we consider it, but, some of the issues were, uh, were discussed, I cannot say in which way it did contribute to structural change...I would say that it did have the impact that people became aware of a strong feeling among people about certain issues. 


\section{Censorship and boundaries}

Cathy regards the right of freedom of speech as essential for academics and although she admits that rumours of censorship do exist, she strongly denies any censoring by herself or even a vindictive attitude of management towards forum participants:

Researcher: Did you get the feeling that people say, yes, but the [forum sic] is censored and now we cannot say what we want?

Cathy: You know, one or two people said that, especially Andrew, suggested, strongly suggested that it is censored, but it is not true at all, I myself did sometimes not get the chance to get on the [forum sic]... but uh, I always had the feeling that there were people on the campus who think that management gets up early in the morning and figures out especially how they will make life intolerable for that guy's life.

With previous knowledge of incidences where participations did disappear shortly after publication, the researchers took the opportunity to explore the reasons for censorship. Although the forum provides the means for the voice of the people to be heard, Cathy indicates that there are constraints which inhibit the act of speaking out (Figure 1:2). Participants should be aware that the public nature of the forum creates the circumstances for voices both to be heard and to be reacted on. Cathy phrases the reaction, however, as "repudiation," indicating that precarious or risky participants should expect just that. In a way she does subvert her own opinion of the freedom the forum offers by resorting to the panoptic view of the forum as a means to see what "the people" are thinking, offering the opportunity to control or "repudiate" those participants. She assumes that participants should know the limits of their participations and the "prudent" boundaries that regulate both the content and the way of their acts of speaking out:

Cathy: look, I see here is the Big Brother syndrome, uh... if you are very afraid...that what you say might be used against you, then it would now of course be the prudent path not to say it... or in a different way... when you publish on the [forum sic]... with your name, then it feels to me a bit like throw it down the gauntlet, uh... you want reaction and you will get reaction, if you come afterwards and say yes, but wow, the guys clamped down on me... it was never my approach to clamp down or to harm someone about things he... on the [forum sic], I did in any case not see everything, uh, things which became apparent, uhm, I never saw myself in the role of Big Brother or Big Sister, not at all.

\section{Decorum and academic finesse}

In addition to the reaction which participants should anticipate, Cathy prescribes the concept of decorum for academics (Figure1:2). This means that they should be self-regulatory and make informed statements on the forum with academic finesse. In this regard she redefines the nature of the forum from being a therapeutic, fun space to a formal environment where decorum is expected. The decorum of a formal environment requires the use of a proper language, it requires the consciousness of civil norms and the proper address of coparticipants and it could possibly temper free speech:

Cathy: Look, it is a very difficult thing, uh, one would want academics to exercise an amount of decorum, this is to me quite, uh, a concept which we learned quite a bit about in drama, but it is a concept which I...very widely, uh, your decorum means that you have a proper judgment, about what you can say in public and about what you cannot 
say, uh, I know many of us might perhaps be deeply persuaded about something which you just do not blurt out and broadcast, it can be offensive.

Cathy leaves the door open for radical ideas to be conveyed on the forum, as long as they are conveyed by the choice of the correct register. She indicates that academics should be able to formulate their statements properly and be aware of the significance or possible reception of their statements, something she doubts happens. Stephen is one of the participants who Cathy distinguishes as a "solid" academic (Figure 1:4) whose participation is especially motivated by his foreign status. She agrees with most of his views, perceiving him as her alter ego who can recognize which issues are pertinent. His style of presentation (Figure 1:2) is praised, exhibiting the finesse she expects from an academic:

Cathy: I must say that uh, especially Stephen, uhm, I was partially responsible for uhm, bis appointment at the university...I thought it is very important to bring in another voice... and he did not disappoint me, uhm, I liked, I often supported his views, and I thought, uh, that he verbalized what I would have verbalized if I, uh, could speak totally independently...but I thought Stephen's voice was necessary...he, uh, writes well, he writes witty, he recognises things, now, of course it is, when one is a bit of the lefty on the campus, I had for many years the reputation of being the lefty, uh, of course it is a bit exaggerated, of course one does not agree with everything he says...but I always thought Stephen's views were probably the most nuanced, and he uh focused on the right things...I think he is an asset to the university...I do think...uh, his voice was very necessary, within the context of his appointment but also in the broader campus.

\section{Balancing loyalties}

Over time, Cathy dealt with former colleagues (Figure 1:4) who criticized and insulted her co-managers. This caused strained relationships and a difficult act of balancing previous and present loyalties. She did tactfully persuade one former colleague into a public apology on the forum:

Cathy: Because we are on a good terms with each other, and therefore I found it very difficult to tell him, uh, you know what, uh, I really think that it's... the ball is in your court, he is not cross with me, we still are very good friends.

As Cathy judged Francois' criticism of her co-manager as insulting, it disappeared from the forum within a few minutes of its publication. His first forced attempt at apology which he presented as a statement of his persuasion also vanished. Cathy did not appreciate Francois' use of the forum to address the specific issue and felt that, on the basis of their friendship, he could have approached her personally. A critical reflection on the favouring of a co-manager above a former colleague and the benefit of a former friendship in addressing and alleviating a difficult situation was present in the conversation with Francois, but absent in the interview with Cathy. The superior position of management being better informed than staff was played as a card, viz. that Francois' misjudgement was because of a lack of information:

Cathy: That is also why I thought with Francois, oh no, Francois, I thought you are a bit better than this, don't act on uh incomplete information.

During the interview with Francois, he did not refer to himself being ill-informed, and in the interview with Cathy, the fact that censorship did take place was also not alluded to. If a lack of information caused the uproar, no steps were taken to inform the readers of the forum of the correct facts to put the events in perspective. 
Cathy finds criticism from Andrew, a previous colleague, (Figure 1:4) to be unfair, in need of editing and also uninformed and repetitive. She claims that participants need to edit their posts, to be sure of their information and to present it with finesse and decorum (Figure 1:2). Some utterances did not meet these requirements, such as Beth's, but her perceived racist declarative participation did go uncensored and her opinions were perceived as instrumental for the existence of an authentic, lively debate:

Cathy: On the other side, concerning Beth, it was to me...I did not necessarily agree with opinions, but I just thought that it is good, there must be space for lively debate.

Beth's participation is especially seen as a transgression of decorum and lacking in academic finesse (Figure 1:2), thereby risking the name of university:

Catby: It can bring the university's name in discredit, and so, and ub, I would in an ideal world that a lecturer know which decorum he must practise, where is his, where is the finesse, the academic finesse to know, oh no man, you don't make, you don't make a statement like this, but, when someone then uhm does it...then one has to handle it carefully, I am very careful for uh censorship.

It does seem however, that voices are judged as uncomfortable when they move too close to managerial concerns and preference is given to the safe middle ground of tempered views:

Cathy: One concept which had been driven especially by uh Andrew, and he also had his accolades who joined him...the one concept which had been driven very much was managerialism...Andrew always has a good case, but he always takes it to the extreme... but one always again has to move a bit to the middle.

In describing an ideal world of informed academics who participate with decorum (Figure 1:2), Cathy perceives Stephen as someone who comes close to these proponents of ideal speech: "but I always thought Stephen's views were probably the most nuanced, and he...focused on the right things." Cathy concedes that his views might be exaggerated, but still they are preferred to those who have extreme positions: "of course it is a bit exaggerated, of course one does not agree with everything he says."

In addition to the ideas Cathy endorses about academic finesse, self-regulation and decorum, echoes of the proponents of the ideal speech bearing on the universal common good underlying and directing democratic discourse are apparent in Cathy's conclusive reflection:

Cathy: And therefore ideas are to me... and lately there plays something in my head, which I had as a sort of a mantra, I used it in my first speech... and I used it again in my farewell speech when I said...people and things are temporal, but ideas and values are eternal.

It would be unfair to ignore the stress conflicting loyalties exerted on a former academic in management, and especially for a woman who had to deal with a management corps which comprised mostly mono-cultural men. In this sense, the power which resides in the larger contexts of the institution and the perception of the university's socio-cultural position cannot be denied. Cathy can be seen as someone who is subjected to, and also actively exercises, the dominant discourse. The dominant discourse is imbedded in those structures within which the university is perceived to be located. Wodak (1996) refers to the powers above discourse, a state of affairs which explains why the dominant discourse is mirrored in external interventions in the forum. It is therefore interesting to note the irony in the touchiness of 
management about criticism on the forum if they distinctively prefer to dismiss the forum's existence or importance.

\section{Those who oppose censorship or moderation}

\section{Acts of internal moderation}

As a person who is alien to the context of the university, Stephen is in conflict with the old dispensation and its sympathizers and this conflict serves to motivate his participation (Figure 1:1). He functions unknowingly and in an unofficial sense as an internal moderator, as he sets the style and tone (Figure 1:2) for others to follow and he criticizes those who seem not to comply with the form or content of his participation:

Stephen: Beth, unfortunately for you, more questionable information does not make an argument based upon questionable information any less questionable.

He especially expects his opponents, such as Beth, to be as rational as he is, to present arguments with the type of evidence he approves of, thereby assuming a patronizing attitude (Figure 1:4):

Stephen focuses on her lack of informedness, her doubtful sources of information, and her deficient argumentation. The larger part of his participation is marked by the presentation of information which illuminates certain aspects of Beth's lack of knowledge, thereby educating her and the readers. His language bears some evidence of an emotional attitude defined by the security and authority that Stephen's informative style affords. This also makes clear his bias. He describes her as under-informed, minimizes her evidence and judges her incapable and not in a position to make authoritative statements (Postma et al., 2012a).

Stephen resorts to what he himself confesses as "hermeneutic bullying" in the following address:

Stephen: Explain in less than 500 words how BEE [Black Economic Empowerment] and/or Equity Employment is racist. Listing endless examples is not good enough, use them, make an argument, build something convincing by clearly explaining how it is that the evidence that you are presenting supports the assertion that you are trying to make. That is called reasoning, and it is the most important part of academic writing (Postma et al., 2012a: 16).

\section{Ideas about censorship}

Stephen disagrees with the censoring interventions (Figure 1:4) on the forum, having a different concept of what censorship is from which is held locally:

Stephen: I have a different notion of free speech that is commonly upheld in South Africa, in South Africa there's certain things that you definitely can't say, we have the category of hate speech, and...I don't know if I really agree with the category of hate speech, as we uhm... as we have it, it's problematic in all sorts of ways, because you can't really insult a category of people, because a category of people doesn't really exist. 
He does not condone the disciplinary action which was taken against Beth for her perceived racist opinions:

Stephen: Well you know, we don't think there should be a disciplinary act against [Beth sic] because we think that she brings to the discussion a sort of popular position and that the discussion is more important than that, uhm, but then by this time I think the person...it was John who made the complaint, and he was very angry and very adamant that that sort of thing should not be tolerated and we differed a bit on that.

Stephen prefers opposing participants to rather solve an issue internally than expect an external agent to address the problem. He however resorts to a form of dominance in the way he addresses those who oppose his views. He acknowledges his bullying of his main opponent and the power play of ideologies present in the forum, creating the perception that the forum is a playfield. He refers to his participation as trolling, which, contrary to the negative impact he alludes to, was never censored:

Stephen: I think in some ways it was sort of slightly more a sophisticated form of trolling, really, it was at first then I pop up and say this prayer stuff is terrible, all this religion is crap, we should get rid of it and people immediately I think see that as an extremist position and you know, that coloured the rest of my commentary, and if I can do things over again, I possibly wouldn't be as hard about, hard core about as when I started.

It is evident from the above quotation that Stephen became aware of his extremist style. In rethinking his participation, he eventually assumed a self-regulatory position to his style of interaction and became less extreme.

\section{Those who condone practices of moderation}

John expects action to be taken against racist remarks, being intensely aware of the hegemony inherent in these types of participations (Figure1:1). He perceives the finding of racism against a participant as a small victory but expresses doubt about any disciplinary action taken:
John: Well, if I have to look at one small victory, that the office of... what is the office's name, something like...let's call it something like the human rights commission of the university, that office made a finding in my favour, that one of the participants was racist and that there were judgments, hate speech, so there was a piece of justice which triumphed, the finding alone, but the recommendation that justice was seen to happen, about that I know nothing, I do not know if the person literally was held liable, that I do not know.

John's victory can be seen in the context of his expectation for the institution to transform. An external moderation or a finding in his favour is seen as tangible evidence of a serious commitment to change. He also applies a form of internal moderation in referring to Beth's arguments as a shaky "stream of logic" which she supports with "quasi-academic references". In this sense his exclusion of her is based both on moralistic and rationalistic grounds:

John: With your acutely racist opinions and your quasi academic references, Beth, you are now opening a can of worms about your and other colleagues' similar opinions about us, your black colleagues. Your "research" and your own persuasions do now prove that black people are of a lower intellectual capability than whites and Asians. Your stream of logic (very shaky, I must add) lead me now to the conclusion that black colleagues 
therefore: 1. Must be very thankful that we are tolerated in your white western piece of pride of a university, 2. are not of equal intellectual ability to the white and Asian colleagues, 3. Must not complain that much about the supposed racism and other unwanted spin-offs of the western thought paradigm

In contrast with his exclusive moralistic discursive relationship with Beth, John portrays an inclusive view of the forum as a place which could affect catharsis:

\begin{abstract}
Andrew withdrew from the discussion on racism, as it declines to a level of a shouting competition. Catharsis is good colleague. It prevents consuming illnesses like cancer and diabetes (according to some medical practitioners), but overall it gives psychological relieve and probibits the building up of methane and other gases which clouds the mind. So, the soapbox of Discussion Forum has space for another shouter.
\end{abstract}

His moralistic condition for catharsis however, is that racist participations should be excluded, as seen in his wish for disciplinary action against those who practise hate speech such as Beth. Beth does however make the same attribution of hatefulness to him:

Beth: John, your outspokenness about all imaginable racist incidents bothers on the maniacal. Your assumptions about what racism is, is precisely the reason why $I$ condescend to communicate with you. Your hatefulness against everything which the [institution sic] was and against those who work and study here, take notice, white people, is clear in all your arguments.

\title{
Those who were subjected to moderation
}

Beth and Francois were participants who experienced the censoring of their posts by management (Figure 1:4). Each experienced the censoring differently. It caused Beth to become more resolute and persistent in her participation, while Francois eventually understood the censoring as a signal that any discourse which is worthwhile is made impossible. He therefore withdrew from a constructive participation in discourses on the forum.

Beth's motivation (Figure 1:1) to participate lies in her persuasion that she represents the silent voice of the majority of middle-aged white men in her opposition to the dominant voices of the liberalists on the forum. On the basis of her perceived racist opinions, she was forced into an acknowledgement of racism, which she refused to do. The episode did not cause her to rethink her position but only made her more resolute. She even quoted a letter of management on the forum to prove that opinions on the forum are indeed censored and acted against by management, thereby casting doubt on the freedom of speech participants presume they have:

Researcher: Concerning management who took action against you, what is your feeling about it? I see that you quote management, what do you feel about it?

Beth: $\quad$ I said that time, see the worry in my eyes, and today exactly the same.

Researcher: So you were not even afraid?

Beth: $\quad$ No, I did write again as you know.

Researcher: So, you were not silenced, you... 


\section{Beth: $\quad$ Mmmmm...}

Researcher: Would you say you rather were encouraged?

Beth: $\quad Y e s$, yes yes, if someone tell me not to do something, then I will do it, I really did, I have no, uh, anything which I say from conviction, and on which I stand, I stand and fall there, I do not care what the consequences are.

She especially despises the moralist position of management, referring to their higher moral ground, while her own morality is frowned upon. She acts from her persuasion which she regards as the absolute truth. The internal moderation which her co-participants exercised in one thread could have been more successful to bring Beth to reflection than the external acts of management which only caused antagonism.

Francois, a former colleague and friend of Cathy's, concedes that their friendship facilitated Cathy's intervention between himself and a co-manager he criticized on the forum. He does however indicate the amiable forcefulness of the situation:

Francois: Yeah, the rector back then, who is Cathy, who is a close friend as well, uhm and she tried to mend the pieces, and she asked me, maybe I was the more flexible person in the whole equation I guess, but I think she also... I think she, I wouldn't say she emotionally blackmailed me, but, you know, there wasn't any other solution for me (Postma et al., 2012b).

He reflects on the trauma the event caused and the uselessness of participation:

Francois: Yea, completely, and I didn't want to, you know back then it was taking a toll on my family as well, as it was the subject of conversations for a while and obviously because of the emotional affect that you derive from such a situation, so, after this episode, I saw that, well, what can you do anyway, you can use the [forum sic] as much as you want, but it is obviously controlled in many ways, and, and you can't convince the people of your point.

The Foucaultian panopticon (Rouse, 2003) is significant here in the opportunity which the forum offers for management to exert control. This control makes the free debating of ideas and even the raising of "uncomfortable" issues impossible. From here on Francois becomes less engaged and reverts more to trolling and ridiculing, as he perceives fruitful debate as impossible.

\section{Those who fear censorship and those who speak out}

In contrast to employees who are born and bred within the system, those who are alien to the context, like Francois and Stephen, do not respect the local morality, but rather by way of trolling and ridiculing they show their disrespect to the "insane" upholding of the status quo. Their foreign status and their disregard for negative reactions from co-participants make them fearless and courageous to speak their minds. Francois indicates his sympathy for the hesitance of locals to speak out and finds himself like Stephen in the fortunate position of coming from a culture where critical discourse is alive:

Researcher: But did people respond to you positively, say well, we agree, but we won't write on the [forum sic]. 
Francois: I have had a bit of that, we are not talking about some messages, maybe five or six, messages over the years, saying well, you know, we sort of agree with you, but we don't have the guts to write on the [forum sic]. Yeah, and then I can understand, you know, if I were them, I would have exactly the same grievances, and the same hesitations, as I said, I am in the very fortunate position, I think Stephen will share this, because he is English speaking, he comes from Cape Town, so in many ways he is an outsider as well, and as an outsider I carry with me the reputation of my country, you know, in France we tend to discuss everything,... in Europe, there is a culture of critique, rather than embracing any kind of self-propelled truth.

Peter, who comes from Europe, has no fear in speaking out and alludes to the fact that locals do not speak out, as they fear dismissal. He also indicates the minimal existence of true critical discourse, especially among students, and finds its absence strange, especially in an academic environment where everything should be questioned:

\begin{abstract}
Peter: There isn't much discussion amongst students also, here, the university, must according to me be an institute where lot of discussion take place, we must actually doubt everything in research, and it does not happen, and eventually, when you look at the [forum sic], how many people are really participating, it's only ten or twelve, it's a few, but what I do know is that many people read it, so around the forum, it is ... many people [say sic] yes, we agree with you, but there might be a fear to take part, I do not have it, I love discussions a lot. But I think the fear of people not to... because I also have pal, a colleague of mine, he has explicit opinions, but he will never, never write on the [forum sic] never, he is afraid.
\end{abstract}

\title{
Proposals
}

Several contradictions are evident in the forum between what people propose and what their actions are, or a tension is marked between what Habermas refers to as linguistic acts and social interaction (as cited by Čečez-Kecmanović, 2001). What people propose to be ideal in their speech acts is not echoed in their social interactions. Cathy proposes that the forum should serve as a space for employees to view their concerns, but as soon as these concerns become uncomfortable for management, those voices are silenced.

If participants experience discomfort, frustration or indignation, they are expected to express it with decorum and finesse, a type of ideal speech which Young (2003) alludes to as quite an unrealistic expectation. The type of interventions from management to solve conflict is typified as an intervention to sidestep conflict by forcing the weaker party "amicably" further into a subordinate position to acknowledge guilt where no transgression took place. The perceived lack of information in opponents' actions serves as a rationalistic form of domination to discard their participation. This is also evident in the oppressing interactions among participants themselves. In this regard, Stephen's view of hegemony is contradictory; he opposes censorship in favour of freedom of speech, but simultaneously dominates the forum and alienates other participants with rationalistic devices, such as minimalising and stereotyping his opponents.

There are also contradictions in John's views and actions. He upholds the ideal that the forum should promote discourse, but the reality of speaking out proves too close to home. He proposes to tolerate racist remarks for the sake of debate, but nevertheless wants management to intervene and discipline those who make it. His motivation to participate is to withstand those who are disrespectful and have unemancipatory views about those who are 
not of the colour, race, religion, etc. they are, but in the same line of thought he also wants them to be silenced.

John views himself as a representative of the injured party in discriminatory racist declarations and presumes that restitutive action has been taken by management, but the moral coherence is distorted concerning the actualization of justice when he is misled into assuming that his charge of racism has been acted upon.

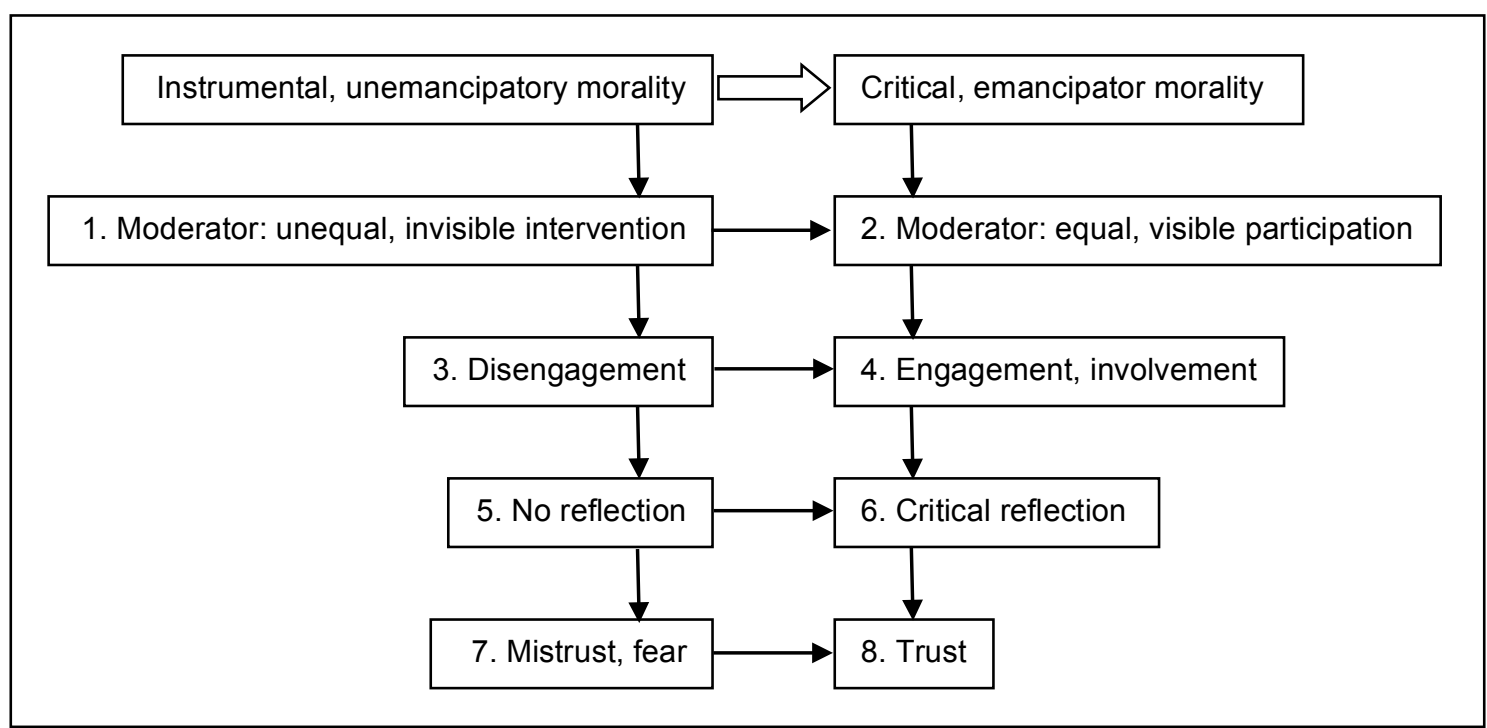

Figure 2 The influence of the moderator on participant emancipation

The perception and practice of morality is strong in the forum and it seems from the above description that the theory and practice of morality are in conflict. One can assume that a critical form of moderation could solve this tension. In the following paragraphs, some proposals are made to move to a more emancipatory form of moderation. The following diagram illustrates the elements within participation which are subject to emancipatory change should the moderator employ a visible and equalising strategy. The actualisation of a critical morality is perceived to be dependent on this reconceptualisation of moderator participation.

\section{From rationalistic exclusion towards emotional inclusion}

If the forum pivots around morality as the pervasive issue, then a moderator should focus on establishing a forum which is characterised as being a friendly, inclusive and accepting space. Aristotle held the view that morality cannot exist or be developed without a community of friends: "With friends men are more able both to think and act" (as referred to by Jacquette, 2001; Sokolowski, 2001). One needs friendship to grow and to realize one's potential. The forum can offer the opportunity for people to reach something they are not able to reach themselves (such as the truth), as friendship enables a person to attain something more (Sokolowski, 2001).

If a rationalistic stance in the forum leads to the assumption of moralistic attitudes by participants, the moderator can facilitate the alienation and disrespect which result from the use of rationalistic devices (stereotyping, minimalizing) by acknowledging the emotions 
experienced by those who make deviant and unemancipatory claims. The moderator can by encouraging narratives of life experiences which inform a certain persuasion create an understanding among participants which moves understanding beyond the purely rational to include affective, embodied ways of knowing. Instead of assuming the moralist position of the majority of participants, the moderator aims to bring opposing parties to a better understanding, but not necessarily an agreement. This intervention might also serve to build "reciprocal respect," which Habermas (1990) refers to, among participants.

In addressing participants, the moderator can also employ the rhetorical devices Young (2000) proposes, such as to greet and compliment the participants, something which is absent in an online forum. Many times the issue takes priority and the participant is ignored by those who build the thread. The practice of greeting and complimenting acknowledges the person behind the statement and lends a humane and emotional element to the discussion. By doing this, the linguistic act does not serve to be the only representation of who the person is. Readers construct online identities and these constructs might be a misrepresentation of the real identity. Participants who are not eloquent and do not express themselves in their first language have a disadvantage and might represent themselves inadequately.

\section{From declarative linguistic acts to social interaction}

If the practice of certain styles, such as trolling and ridiculing, serves the purpose not to engage in social interaction, then a moderator can facilitate by moving participants beyond those styles. The moderator can acknowledge the linguistic act and move further by asking what motivates the specific choice of style.

In this specific case study, sensible interaction between participants is absent. This can be seen in the choice of declarative style in the majority of cases. The choice of ridicule, trolling and flaming also does not lead to meaningful and engaging discourse, although some of it might provide comic relief for like-minded readers. Acknowledging the humour is certainly a way to start, but the motive of the participant has to be clarified for proper understanding. Language bantering in the forum often clouds participants' true meanings.

\section{From invisible to visible moderation}

If a moderator is visible and present (Figure 2:2), mistrust and fear (Figure 2:7) of participants who want to speak out, may disappear. It seems as if the doubt concerning the consequences of participation installs more fear and rumours about censorship and flames the antagonism against management. If the motive of moderation is clarification, the transparency of the moderative act could bring more trust.

\section{From censorship to allowing all voices}

Eventually, moderation is not about the silencing or censoring of voices but it should aim to bring opposing parties to better understanding. It does not mean that extreme voices should be made more moderate. Real debate will not take place if everyone has moderate views and if all share the same premises (Young, 1996; Young, 2001). Debate is fruitless if premises are not understood. Although premises can and should be questioned, it seems as if the termination of participation can be ascribed to the fact that premises keep on being claimed and participants do not adjust their views, simply because they are not within a space which encourages it. Instead of finding themselves within a friendly accepting space, the space 
remains competitive and toxic and the participants remain isolated and alienated from meaningful engagement.

\section{From unequal intervention to equal participation}

A moral incoherence is created when the moderator intervenes invisibly and gives preference to or silences participants. A mathematical formulation illustrates the incoherence, based on similar examples offered by Sokolowski (2001). A moral equation obliges the moderator to stand outside a debate between participants, but the real situation in this case study is that an invisible moderator sides with one participant against another, thereby creating a moral incoherence.

\section{From instrumental to emancipatory morality}

If a moderator assumes an equal, visible co-participative (Figure 2:1) rather than an unequal, invisible intervening (Figure 2:2) position, several emancipatory elements can be realised within the forum. The participants can become motivated to become engaged and reflect on their own positions as the moderator sets, as co-participant, an example of amiable engagement (Figure 2:4) and reflective interaction (Figure 2:6). The role of the invisible (Figure 2:1), detached (Figure 2:3) and punitive moderator is replaced by a visible (Figure 2:2), involved co-participant (Figure 2:4) who co-defines and is ultimately co-responsible for the creation of a friendly, inclusive space of mutual trust, learning and development.

\section{Conclusion}

It seems as if the perception of the forum as an outlet of emotion leads management to be afraid of the emotions of employees. It might explain the measures which were undertaken to censor and silence deviant voices and to condone those voices which supported the direction of transformation. Ideas about an ideal world, an ideal institution, the ideal academic and the ideal way of expression can result in enforcing views which support this idealism, and the notion of what is ideal can lead to an oppressive form of management.

Perceiving the forum as the voice of the people brings with it the necessity to listen to what the people are saying in the way they prefer to do it. Formulating rules and restrictions for the style and content of participations eventually disables the potential this form of communication has in the establishment of an institution which truly values freedom of speech, the basic tenet of democracy.

\section{References}

Čečez-Kecmanović D. (2001) Critical information systems research: a Habermasian approach. The 9th European Conference on Information Systems. Bled, Slovenia: Global corporation in the New Millenium.

Dandridge N and Mendus S. (2012) When does freedom of speech threaten the cohesion of a university as a learning community? Should there be any limits on what can be said in a university? http://richmedia.1se.ac.uk/publicLecturesAndEvents/20120208_1830_freedomOfSpeechOnCampus.mp 3 . 
De Laat PB. (2012) Coercion or empowerment? Moderation of content in Wikipedia as 'essentially contested' bureaucratic rules. Ethics of Information Technology 14: 123-135.

Denzin NK. (1999) Cybertalk and the method of instances. In: Jones S (ed) Doing internet research: critical issues and methods for examining the Net. Thousand Oaks, CA: SAGE, 107-125.

Habermas J. (1990) Discourse ethics: notes on a program of philosophical justification. In: Benhabib S and Dallmayr F (eds) The Communicative Ethics Controversy. Cambridge, Mass: MIT Press, 60-110.

Herring S, Job-Sluder K, Scheckler R, et al. (2002) Searching for Safety Online: Managing "Trolling" in a Feminist Forum. The Information Society 18: 371-384.

Hoad TF. (1996) The Concise Oxford Dictionary of English Etymology. Oxford: Oxford University Press.

Jacquette D. (2001) Aristotle on the value of friendship as a motivation for morality. The Journal of Value Enquiry 35: 371-389.

O'Sullivan PB and Flanagin AJ. (2003) Reconceptualising "flaming" and other problematic messages. New Media and Society 5: 69-94.

Postma L, Blignaut AS, Sutinen EA, et al. (2012a) Rationalistic exclusion and power inequality within an online forum of a higher education institution. Journal of Computer-Mediated Communicatiom In press.

Postma L, Blignaut AS, Sutinen EA, et al. (2012b) Reflections on the use of grounded theory to uncover narratives in an online discussion forum at an institution of higher education. International Journal of Qualitative Methods In press.

Rouse J. (2003) Power/knowledge. In: Gutting G (ed) The Cambridge Companion to Foucault. Cambridge: Cambridge University Press, 95-122.

Sokolowski R. (2001) Friendship and moral action in Aristotle. Journal of Value Inquiry 35: 355-369.

Strauss A and Corbin J. (2008) Basics of qualitative research: grounded theory, procedures and techniques, Newbury Park, CA: SAGE.

Turnage AK. (2007) Email flaming behaviors and organizational conflict. Journal of Computer-Mediated Communication, 13. (accessed 23 February 2012).

Urban Dictionary. (2013a) Flaming. Available at: http://www.urbandictionary.com/define.php?term=flaming.

Urban Dictionary. (2013b) Trolling. Available at: http://www.urbandictionary.com/define.php?term=troll.

Van Doorn N. (2011) Digital spaces, material traces: how matter comes to matter in online performances of gender, sexuality and embodiment. Media Culture Society 33: 531547.

Webster L and Mertova P. (2007) Using narrative inquiry as a research method, London: Routledge.

Wodak R. (1996) Disorders of discourse, London: Longman. 
Young IM. (1996) Communication and the other: beyond deliberative democracy. In: Benhabib S (ed) Democracy and difference: contesting the boundaries of the political. Princeton, N. J: Princeton University Press, 120-135.

Young IM. (2000) Inclusion and democracy, Oxford: Oxford University Press.

Young IM. (2001) Comments on Seyla Benhabib, situating the self. New German Critique 62: $165-172$.

Young IM. (2003) Activist challenges to deliberative democracy. In: Fishkin JS and Laslett P (eds) Debating deliberative democracy. Oxford: Blackwell, 41-55. 